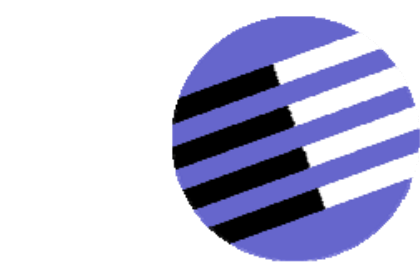

GOVERNANCE AND THE EFFICIENCY

OF ECONOMIC SYSTEMS

GESY

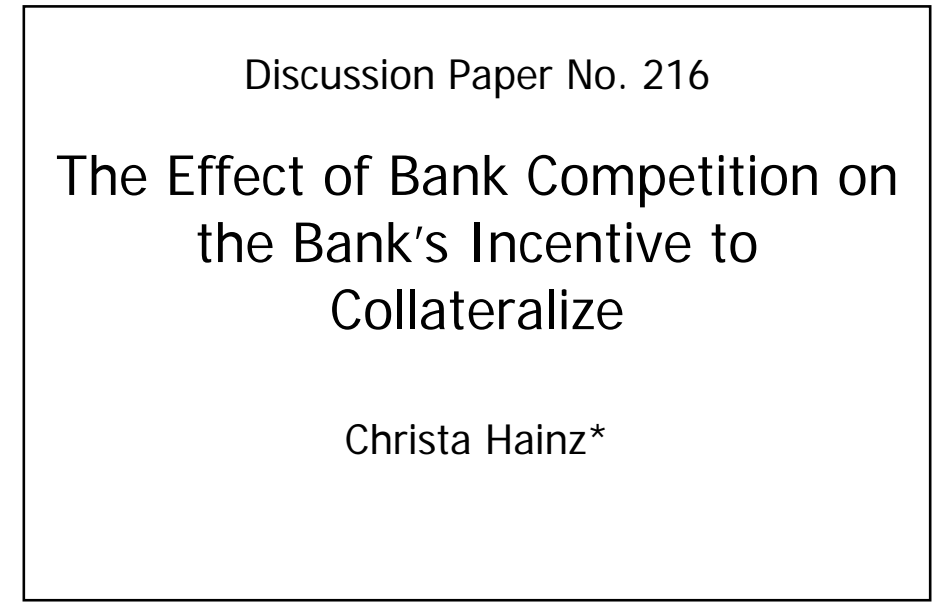

September 2007

*Christa Hainz, University of Munich, Department of Economics, Akademiestr. 1/III 80799 Munich, Germany

Tel.: +49-89-2180-3232, Fax: +49-89-2180-2767

christa.hainz@Irz.uni-muenchen.de

Financial support from the Deutsche Forschungsgemeinschaft through SFB/TR 15 is gratefully acknowledged.

Sonderforschungsbereich/Transregio $15 \cdot$ www.gesy.uni-mannheim.de

Universität Mannheim · Freie Universität Berlin · Humboldt-Universität zu Berlin · Ludwig-Maximilians-Universität München Rheinische Friedrich-Wilhelms-Universität Bonn · Zentrum für Europäische Wirtschaftsforschung Mannheim 


\title{
The Effect of Bank Competition on the Bank's Incentive to Collateralize
}

\author{
Christa Hainz* \\ University of Munich, CESifo and WDI
}

September 4, 2007

\begin{abstract}
It has been argued that competing banks make inefficiently frequent use of collateralization in situations where they are better able to evaluate a project's risk than entrepreneurs. We study the bank's choice between screening and collateralization in a model where banks do not have this superior screening skill. In particular, we study the effect of bank competition on this choice. We find that competing banks use collateral less often than a monopolistic bank because competition will intensify if both banks collateralize. Moreover, bank competition is welfare improving if collateralization is rather costly.
\end{abstract}

JEL-Classification: D82, G21, K00

Keywords: Collateralization, screening, incentives, bank competition

\footnotetext{
${ }^{*}$ Department of Economics, University of Munich, Akademiestr. 1/III, 80799 Munich, Tel.: +49 892180 3232, Fax.: +49 892180 2767, e-mail: christa.hainz@lrz.uni-muenchen.de. The author would like to thank Hendrik Hakenes, Maria Lehner, Monika Schnitzer and seminar participants at the University of Munich and the Swedish Riksbank for helpful comments and suggestions. The usual disclaimer applies. This research was undertaken during a visit at New York University's Stern Business School, which I thank for its hospitality. Financial support by the German Science Foundation through grant HA 3039/2-1 and SFB-TR 15 is gratefully acknowledged.
} 


\section{Introduction}

Collateralization plays a crucial role in financial markets, but policy recommendations concerning the use of collateral are contradictory. The World Development Report 2002 emphasizes how important collateral is for the provision of loans. Therefore, the policy recommendation for less developed countries is to secure property rights in order to establish potential collateral (World Bank, 2001). Nevertheless, there are arguments against collateralization (Jackson, 1986). In a theoretical model, Manove, Padilla and Pagano (2001) show that competing banks demand collateral inefficiently often and thereby reduce the information generated by the banks. They conclude that the banks' capability to demand collateral should be restricted in the case of bank competition. Their model is based on the assumption that banks can generate better information about the success probability of a project than the entrepreneur, which happens, for instance, if firms are overconfident. The evidence whether firms are indeed overconfident is equivocal (for a discussion of the related empirical literature see $\mathrm{Wu}$ and Knott (2006)). ${ }^{1}$ Thus, so far, the theoretical literature does not provide full answers to the question of how desirable collateralization is.

Most likely, banks have superior screening skills in certain segments of the banking market in countries with a "well developed" banking sector. In many countries, banking markets are less sophisticated and, in particular, bank staff is only beginning to gain experience in evaluating credit risk. Thus, banks cannot generate more information about the chances of success than the entrepreneurs. In this paper, we focus on such a situation where banks are not better able to evaluate a project's risk than entrepreneurs. We analyze the incentive of banks to collateralize a loan or to screen the applicant in order to overcome asymmetric

\footnotetext{
${ }^{1}$ Banking with overly optimistic entrepreneurs is modeled in Manove and Padilla (1999).
} 
information on the project's type. In particular, we study how this incentive depends on the specific characteristics of a banking market and the degree of bank competition.

Our model captures different levels of market development. We achieve this by incorporating varying costs of screening and collateral. Collateralization is costly because a deadweight loss arises if the collateralized assets are liquidated. Thus, the better the legal environment (and consequently, the lower the cost of liquidation) and the more liquid the market where the asset is sold, the lower is the deadweight loss. However, through offering collateral a firm reveals its true type. The costs of screening consist of the variable costs of evaluating credit proposals and the expected loss of financing non-creditworthy firms, because the screening technology provides only an imperfect signal on the applicant's creditworthiness. The more experienced the bank, the more precise is the signal. Both a monopolistic bank and competing banks trade off the costs of collateralization relative to that of screening.

From our theoretical analysis, we derive three main results. First, the decision of the monopolistic bank to offer a collateralized contract is, in contrast to the case of competing banks, not distorted. Second, we show that competing banks collateralize credit contracts less often than a monopolistic bank. In the case of two banks, each competing bank obtains positive expected profits if one of them offers a screening contract and the other offers a collateralized contract. The reason is that some degree of asymmetric information prevails as the screening signal is imperfect. However, each competing bank makes zero expected profits if they both offer a collateralized contract. As banks try to maximize their profits their incentive to offer collateralized credit contracts is distorted. Third, our analysis demonstrates that from the perspective of social welfare bank competition may even be preferred. 
This happens for very low liquidation values. In this case, a monopolistic bank offers a screening contract with the option to pledge collateral. Due to the high costs of liquidating collateralized assets, this is expensive in terms of social welfare. In contrast, both competing banks offer a screening contract. Thereby, they generate independent signals and reduce the (social) costs of credit financing compared to the monopolistic case.

Moreover, our analysis shows that the policy conclusions, in particular how desirable bank competition is, depend on the specific features of the banking sector and the environment in which banks operate. The environment influences the liquidation value. The liquidation value is higher if an asset is not firm-specific, if it is sold on a highly liquid market, and if the costs of having an asset liquidated are low. The first two characteristics allow us to compare different types of assets, the last two allow us to compare emerging and mature markets. Only for high liquidation values is the type of contract independent of the degree of competition. For intermediate liquidation values, we obtain the same result as most papers on bank competition, namely that social welfare is highest in the case of a monopolistic bank. If, however, the liquidation value is very low, bank competition increases welfare. Thus, we conclude that in emerging markets (where secondary markets are rather illiquid and the costs of liquidation are high) it is particularly important to have bank competition.

This paper is related to the literature on the choice between screening and collateralization and on bank competition. Before we refer to the literature on the choice of contracts, we explain how different types of contracts solve problems of asymmetric information and how contracts are influenced by competition. Collateral is used to solve the adverse selection problem. Firms with a lower default risk are more inclined to provide collateral. Thus, banks offer contracts with different combinations of repayment and collateral. Through their choice 
firms reveal their default probability (Bester, 1985; Besanko and Thakor, 1987). Collateral is also used to mitigate the moral hazard problem (ex ante as well as ex post) by changing the payoff structure (Bester, 1987, 1994).

Bank competition influences the terms of a credit contract and, as such, reduces the amount of collateral demanded (Berlin and Butler, 2002; Hainz, 2003). At the same time, the possibility of collateralization helps to increase bank competition. Entry barriers which are caused by the information advantage of the incumbent bank (Dell'Ariccia, Friedman and Marquez, 1999; Sharpe, 1990) can be contested by offering collateralized contracts (Sengupta, 2007). Alternatively, new lenders may use credit scoring based on hard information. This new outside option improves the borrower's bargaining position vis-à-vis the incumbent bank. As a result, the incumbent bank's incentive to lend gets distorted. This distortion can be mitigated if firms pledge collateral (Inderst and Müller, 2006).

The seminal paper on screening is Broecker (1999), which analyzes credit contracts when banks receive imperfect and independent signals from screening applicants. If there is bank competition, a winner's curse problem arises. It is shown that the average creditworthiness of those firms which are financed decreases as the number of banks increases. Zazzaro (2005) models the bank's choice of the quality of the screening technology. He argues that contracts should not be enforced strictly. If contracts are strictly enforced, the bank's payoff in the case of default increases and its risk decreases. Consequently, banks have a lower incentive to improve their screening technology.

All these papers take the type of credit contract offered as given. Although collateral and screening could be complements when information about borrowers is generated (like in Inderst and Müller (2006)), in most papers they are substitutes. What are the trade-offs 
between different contractual modes? First, a screening and a pooling contract are compared by Schnitzer (1999a). Banks decide whether to offer a pooling contract to all applying firms independent of their type or a screening contract where banks get perfect information about the firm provided they have invested in costly screening. For low screening costs, banks obviously offer a screening contract. For higher screening costs, however, a bank's decision depends on the number of banks that do not screen. As a result, multiple equilibria occur in which either all banks screen or no bank screens.

Second, Dell'Ariccia and Marquez (2006) argue that banks can offer a pooling contract or a collateralized credit contract. By demanding collateral, banks get perfect information on the risk type of the firm through the self-selection of firms. In this model, the costs of collateralization arise because liquidation of assets incurs a deadweight loss. These results imply that collateralization is the preferred contractual mode if the costs of liquidation are low.

Third, Manove, Padilla and Pagano (2001) (henceforth MPP) compare screening and collateralization; this is the paper which our model is most closely related to. In this model, firms know their type, i.e., whether they have a high or low probability of success. By pledging collateral they can reveal their type to the bank. However, banks could find out the actual quality of firm, i.e., whether a firm is going to be successful or fail, by screening them. Thus, banks can generate additional information by screening applicants. The bank possesses a screening technology which generates perfect information, but causes a cost for each applicant that is screened. In contrast, the costs of collateralization are that not only successful firms receive a loan but also firms which will fail. As a result, a monopolistic bank offers the first best contract because it bears the costs of collateralization or screening, 
respectively. For intermediate screening costs this is a screening contract.

In the case of bank competition, the costs a particular group of firms has to bear depend on the contract offered. If a collateralized credit contract is offered, firms with a high (low) probability of success face a repayment that not only covers their loan but also the expected loss the bank makes through financing the failing firms among the other firms with a high (low) probability of success. If a screening contract is offered, the good firms' repayments must cover the screening costs for all firms. For intermediate screening costs the competing banks offer a separating contract as the firms with a high (low) probability of success prefer a collateralized (screening) contract. For firms with a high probability of success, it is cheaper to subsidize those firms with a high probability of success that in the end fail than to bear the screening costs of all bad firms (with high and low probability of success). At the same time, firms with a low probability of success prefer a screening contract since they would have to cover the losses arising from financing the bad firms, which are more numerous in this category of firms. In this parameter range, however, a screening contract maximizes welfare. Thus, according to MPP, competing banks screen too little.

This result is in line with most of the literature on competition in banking (Cetorelli, 2001, summarizes recent contributions). The majority of papers conclude that competition leads to an inefficient outcome. The sources of the inefficiency depend on the set-up of the model. They can be the duplication of screening costs and the winner's curse problem (as in Broecker, 1990) or the incentive problems resulting out of them that, for instance, lead to insufficient investment in screening by competing banks (as in Schnitzer, 1999a). However, these papers only consider the banking sector. They neglect that the financing costs, which decrease as banking becomes more competitive, have an important effect of the investment 
incentives of firms (Schnitzer, 1999b). The investment incentive determines the development of the real sector of the economy and thereby feeds back into the stability of the financial sector (Boyd and De Nicolò, 2005). In our model, bank competition can be optimal even though we only consider the banking sector and neglect the impact on the real sector.

The result in MPP is quite intuitive given that they assume that banks can generate some additional information. The aim of our paper is to study whether bank competition indeed leads to inefficient collateralization given a banking system that is not capable of generating additional information but aims to overcome the adverse selection problem. We find that competing banks screen less often than a monopolistic bank. The reason is that if one bank offers a screening contract and the other one a collateralized contract, some degree of asymmetric information prevails as the screening signal is imperfect. Therefore, competition is less intense than if both banks collateralize. Thus, the bank's incentive to soften competition drives our result whereas in MPP the inefficiency is caused by the incentive of firms to separate in order to reduce the funding costs.

The paper is organized as follows: in section 2 we set up the model and derive the contract offered by a monopolistic bank. Moreover, we study the optimal contract offered in the case of bank competition and show how the contract depends on the degree of competition in the banking sector. In section 3 , we analyze which contract would maximize social welfare and evaluate the contracts offered in the case of bank competition and in the case of a monopolistic bank from a social welfare point of view. Finally, we conclude in section 4 . 


\section{Model}

\subsection{Set-up}

Before analyzing the credit contracts offered, we describe the characteristics of the borrowers and the banking sector. The number of firms is normalized to 1 ; the share of good debtors is $\mu$ and that of bad debtors is $(1-\mu)$. The good debtors have a project that is successful with probability $p$. In the case of success the project's payoff is $X$, in the case of failure it is 0 . The investment costs of the project are $I$. Thus, the expected payoff of a good firm is $p X-I$, which we assume to be positive. Bad firms will fail with probability 1 . The firms are endowed with an asset endowment of $A$. However, due to the lack of own liquid funds, the firms need to finance their investment through credit.

We consider two different market structures in the banking sector: there is either a monopolistic bank or a competitive banking sector with two identical banks. Banks have two means to discriminate between good and bad firms: they either offer a collateralized credit contract which induces firms to signal their type, or they screen all firms applying for credit by evaluating their credit proposals.

In the case of collateralization, the bank gets a payoff from the collateralized assets that are liquidated if the project fails. There are costs associated with liquidation. Therefore, the liquidation value of each unit of collateral, denoted by $\alpha$, is lower than the continuation value in the firm, i.e., $\alpha<1$. According to the Doing Business Report the recovery rate in most regions of the world does not exceed 30 per cent (World Bank, 2006). ${ }^{2}$ If banks decide to screen, they incur a cost $c$ when screening a firm. By screening they receive a signal which

\footnotetext{
${ }^{2}$ Secured creditors may get a higher repayment, but even their payoff is still remarkably low in the case of failure.
} 
reveals the firm's type correctly with probability $s$, with $s>0.5$.

The timing of the game is as follows: In the first stage, banks decide sequentially which type of contract they offer. In the second stage, the banks determine simultaneously the terms of the credit contract they offer. Modeling the first stage as a sequential decision makes the exposition of the results clearer (because we do not have an equilibrium in mixed strategies) but does not change our findings (see discussion in section 3.2).

\subsection{Monopolistic Bank}

A monopolistic bank makes a take-it-or-leave-it offer to the firms. It can offer a screening contract, a collateralized contract or a screening contract with the option for all those firms that generated a negative signal to pledge collateral. The decision of the monopolistic bank to offer a credit contract is based on the profit each of the different contracts generates. We will study the different contracts and then determine which one is offered. In our set-up, the monopolistic bank can offer a screening contract with the option to collateralize for all those firms that generated a negative signal. In many credit markets, however, banks decide either to accept applicants under the initial conditions or to reject them (Saunders and Thomas, 2001). Through this set-up, we put the monopolistic bank into a more favorable position than competing banks and thereby make some of our results even stronger. We discuss the implications of this assumption in section 3.2.

\subsubsection{Collateralized Credit Contract}

We first study a collateralized credit contract. Collateralization implies that the firm repays an amount $R$ in the case of success and that it loses collateral in the amount $L$ in the case of 
failure. The credit contract has to be designed in a way that the bad firms have no incentive to demand credit. This is reached through collateralization. The incentive compatibility constraint for a bad firm can be written as:

$$
\begin{aligned}
I+(A-L) & =A \text { or } \\
L & =I
\end{aligned}
$$

If a bad firm receives a loan in the amount of $I$, it will lose assets in the amount of $L$ as the project fails with certainty. Therefore, it is obvious that the amount of collateral that prevents bad firms from applying for credit is $I$. The repayment $R$ is determined according to the participation constraint of good firms:

$$
\begin{aligned}
p(A+X-R)+(1-p)(A-I) & \geq A \text { or } \\
R_{M}^{L} & \leq \frac{p X-(1-p) I}{p}
\end{aligned}
$$

If the project is successful, the good firms repay $R_{M}^{L}$ from the payoff $X$ they generate. In the case of failure, collateralized assets in the amount of $I$ are seized by the bank. The expected payoff when the investment is credit-financed has to be at least as high as the payoff from not investing. Since the monopolistic bank can extract the whole rent by demanding $R_{M}^{L}=\frac{p X-(1-p) I}{p}$ the firm retains $A$.

For the monopolistic bank the collateralized credit contract yields the following profit, denoted by $\Pi_{M}^{L}$ :

Lemma 1. The expected profit of a monopolistic bank if it offers a collateralized credit contract is $\Pi_{M}^{L}=\mu(p X-(1-p)(1-\alpha) I-I)$.

As Lemma 1 shows, the monopolistic bank can extract the total rent from the goods firms. However, it also has to bear the total costs of collateralization because in the case 
of failure, which happens with probability $(1-p)$, the collateralized assets yield a payoff of $\alpha I$. This implies that there is a loss in the case of liquidation in the amount of $(1-\alpha) I$.

\subsubsection{Screening Contract}

If the monopolistic bank decides to screen its applicants, it has to incur the costs of evaluating the credit proposals of $c$. As the quality of the signal is imperfect, only a fraction $s$ of the good firms will be financed (all the firms that generated a positive signal). Even more importantly, a fraction $(1-s)$ of bad firms gets credit as the bank receives a positive signal about their quality. The monopolistic bank can extract all rents from the good firms. The following lemma states the bank's profit, denoted by $\Pi_{M}^{S}$ :

Lemma 2. The expected profit of a monopolistic bank if it offers a screening contract is $\Pi_{M}^{S}=\mu s(p X-I)-(1-\mu)(1-s) I-c$.

\subsubsection{Screening Contract with Collateralization}

The monopolistic bank is aware of the fact that in the case of screening it denies creditworthy applicants loans because the result of the credit evaluation is false. Therefore, the monopolistic bank may offer a collateralized credit contract to all firms that generated a negative signal. As shown above, the conditions of a collateralized credit contract are such that only good firms have an incentive to accept this contract. The following lemma shows the bank's profit, denoted by $\Pi_{M}^{S L}$ :

Lemma 3. The expected profit of a monopolistic bank if it offers a screening contract and a collateralized credit contract to all firms which generate a negative signal is $\Pi_{M}^{S L}=$ $\mu(p X-I)-(1-\mu) I(1-s)-c-(1-s) \mu I(1-p)(1-\alpha)$. 
In this case all good firms receive a loan. Since the screening process is subject to mistakes also a share of $(1-s)$ bad firms are financed by the bank. Besides the screening costs, this expected loss constitutes the costs of a collateralized contract. For all the good firms that receive credit with collateralization the costs of collateralization are born by the monopolistic bank. The bank has an incentive to offer the additional possibility of collateralization if the expected costs of collateralization are below the return generated by financing the good firms with the bad signal, i.e., $(p X-I)-I(1-p)(1-\alpha) \geq 0$. We assume that this is the case.

\subsubsection{Contract Offered}

We can derive which credit contract is optimal for the monopolistic bank by comparing the profit levels. The threshold value of $\alpha$ where the decision to offer a contract changes is denoted by $\alpha_{M}^{K}$.

Proposition 1. The monopolistic bank offers a collateralized credit contract if $\alpha_{M}^{K} \geq$ $\frac{\mu I(1-s p)-(1-s) I-c}{\mu s I(1-p)}$. Otherwise, it screens all applicants and finances good firms with a negative signal through a collateralized loan.

Proof: See the Appendix.

The monopolistic bank faces the following trade-off: in the case of collateralization, the bank must bear the costs associated with the liquidation of the collateralized asset. In the case of screening, the monopolistic bank has to incur screening costs for each applicant. More importantly, it faces the risk of receiving an incorrect signal, which means that it finances bad firms and misses financing good firms and thereby foregoes extracting rents. The monopolistic bank can avoid denying credit to good firms and thereby extract rents from them by offering a contract with screening and collateralization. For this reason, the screening 
contract is dominated by the combined contract and is not offered. Whenever the liquidation value of collateral exceeds the threshold value $\alpha_{M}^{K}$, it is optimal to use collateralization.

If the costs of screening $c$ increase, the threshold value decreases. As expected, the critical liquidation value increases as $s$ and $I$ increase. A higher $I$ means that the costs of liquidation increase as the amount of collateral increases. A better screening technology reduces the losses of financing bad projects. Our model shows that the degree of collateralization is not only influenced by the liquidation value of collateral but also by the capability of the bank to generate information through screening.

\subsection{Competitive Banking Sector}

We capture bank competition in a model with two banks that engage in Bertrand competition. We assume that firms can apply for only one contract at each bank (MPP make a similar assumption). Firms will apply at both banks and choose the best offer because they do not have any costs of submitting credit proposals. Before we can study the type of contract offered in equilibrium, we must first derive the terms of the credit contract if both banks collateralize, second the terms of the credit contract if both banks screen and finally the terms of the credit contract if one bank screens and the other bank collateralizes. Then, we determine the conditions under which a particular contract is offered. However, due to the assumption that firms can apply for only one contract at each bank, banks do not offer combined contracts where firms are screened and those with a negative signal have the chance to get a loan when they pledge collateral (which is in line how Saunders and Thomas (2001) describe many credit markets). ${ }^{3}$

\footnotetext{
${ }^{3}$ An alternative explanation of why banks do not offer combined contracts are fixed costs for developing either a screening technology in addition to expertise in collateralization (or vice versa). Suppose that
} 


\subsubsection{Both Banks Collateralize}

As shown for the monopolistic bank, the incentive compatibility constraint of the bad firm implies that collateral $L=I$. Since banks are competing, they will demand a repayment $R$ that guarantees that they are making zero expected profit, i.e., the bank's participation constraint is:

$$
\begin{aligned}
p R+(1-p) \alpha I-I & =0 \text { or } \\
R & =I \frac{1-(1-p) \alpha}{p}
\end{aligned}
$$

The good firm's participation constraint is always fulfilled as we have assumed that the investment is efficient, i.e. $p X-I>0$. The payoff a firm receives with a collateralized credit contract (superscript $L$ ) is denoted by $P^{L}$, the bank's profit by $\Pi^{L}$. Note that we do not use subscripts in the case of bank competition.

Lemma 4. If the banks offer a collateralized credit contract, a good firm receives an expected payoff of $P^{L}=p X-I(1+(1-\alpha)(1-p))$ and banks make zero expected profits, $\Pi^{L}=0$.

\subsubsection{Both Banks Screen}

The signals that banks generate are imperfect and independent of each other. ${ }^{4}$ It is quite realistic to use imperfect signals because the empirical literature shows that banks rate banks could offer a combined contract and screening is relatively cheaper than collateralization in generating information. Then a bank providing a collateralized credit contract would finance only a share of $(1-s)^{2}$ good firms since firms accept a collateralized credit contract only if they do not receive an offer after being screened by both banks.

${ }^{4}$ The set-up of this section is similar to the model by Broecker (1990). 
the default risk of a particular borrower differently (Jacobson, Lindé and Roszbach, 2006; Mitchell and van Roy, 2007). In a study on Sweden, the authors take into account that the banks use different rating classes which might reduce the correlation between their screening results and they correct for all possible distortions caused by this fact. Nevertheless, the correlation varies between 0.75 and 0.8 (Jacobson, Lindé and Roszbach, 2006). In a study on Belgium, a simulation shows that "[...] between sixteen and twenty percent of applicants would find their loan applications rejected by one bank but accepted by the other [...]" (Mitchell and van Roy, 2007, p. 4).

The timing of events for the second stage (the determination of the interest rate) is as follows: The banks announce the interest rates. Firms submit their credit proposals at both banks. Like above assume that there are no costs for the firms of submitting a credit proposal. The banks screen them, and accept those with a positive signal. Firms choose the most favorable credit offer (and we call these firms the first group), implying that firms accept any credit contract offered if they receive only one offer (and we call these firms the second group). There is no information sharing between the banks about the signals of a particular customer. Of course, the banks are aware of the adverse selection problem existing between them. They take into account the fact that this second group of applicants is of poorer quality, although they do not know which particular firm has been rejected by their competitor.

The banks determine their repayment as follows. Banks are willing to offer credit with certainty if the expected payoff from demanding the highest repayment $X$ and being undercut by the competing bank is non-negative. We assume that this is indeed the case. Formally, 
this condition is given by:

$$
\begin{aligned}
\bar{\Pi}^{S} & =\mu(1-s) s(p X-I)-(1-\mu) s(1-s) I-c \\
& =(1-s) s(\mu(p X-I)-(1-\mu) I)-c \geq 0
\end{aligned}
$$

The expected profit of demanding $X$ consists of the rent, $p X-I$, that a bank can extract from those good firms that have been denied credit in the first round and now are screened to be good. However, the bank also has to cover the loss made with bad firms that have been denied credit in the first round and on which it receives a favorable signal, i.e., $(1-\mu) s(1-s) I$. Moreover, the evaluation of each credit proposal causes a cost of $c$ since all firms apply at each of the two banks.

Each other repayment has to generate the same return for the bank. This condition can be used to derive the lowest repayment, denoted by $\underline{R}^{S}$. However, for the repayment $R^{S}$ there is no equilibrium in pure strategies. Suppose both banks offer the same repayment. Then, applicants from the first group would go to each bank with equal probability. Suppose that this $R^{S}$ yields zero expected profit for the banks. Then, marginally undercutting would discontinuously increase the profit of a bank because all applicants from the first group would apply for credit at this bank. By undercutting, the bank can improve the pool of applicants significantly and therefore makes a non-negative expected profit. This would hold for all $R^{S} \geq \underline{R}^{S}$. No bank would reduce the repayment below $\underline{R}^{S}$ because it makes a negative expected profit although it serves the whole market. For the competitor the optimal answer would be to demand $X$ from all applicants in the second group, which are rejected by its competitor. However, in this situation demanding $\underline{R}^{S}$ is no longer optimal. Thus, no equilibrium in pure strategies exists. The mixed strategy equilibrium is described in the following proposition: 
Lemma 5. The mixed strategy equilibrium has the following features: The banks demand a repayment from the range $\left[\frac{s(\mu p X-I)(1-s)+I(1-s(1-\mu)-\mu(1-s))}{\mu s p}, X\right]$, according to the following cumulative distribution function $F(R)=\frac{\mu s^{2}(p R-I)-I(1-\mu)(1-s)^{2}-\mu s(1-s) p(X-R)}{\mu s^{2}(p R-I)-I(1-\mu)(1-s)^{2}}$.

Proof: See the Appendix.

The following lemma shows the firm's expected payoff, denoted by $P^{S}$, and the bank's expected profits. $E\left(R^{S}\right)$ denotes the expected repayment.

Lemma 6. If the banks offer a screening contract, the expected payoff of a good firm is $P^{S}=$ $p\left(X-E\left(R^{S}\right)\right) s(2-s)$ and banks make an expected profit of $\Pi^{S}=\mu(1-s) s(p X-I)-$ $(1-\mu) s(1-s) I-c$.

Proof: See the Appendix.

The advantage of bank competition for a good firm is that it has the chance to receive credit from bank 2 if it is denied credit by bank 1 and vice versa. The probability to receive credit is thus $s(2-s)$. The repayment is influenced by the screening quality of the bank. The repayment determines the extent to which bad firms are subsidized by good firms. It also influences the banks' profit which they can earn by serving the good firms in the second group. The latter profit level determines the expected bank profit $\Pi^{S}$.

\subsubsection{One Bank Screens, One Bank Collateralizes}

Suppose bank 1 offers a collateralized credit contract and bank 2 offers a screening contract. In this case, the repayment bank 1 demands is denoted by $R^{L S}$ (the first superscript shows the choice of the bank we consider and the second the competitor's choice). The timing of events is equivalent to what was described in section 2.3.2. The firms behave as follows: 
Firms submit their credit proposal at both banks simultaneously and the banks decide on the contract terms. Firms demand credit from the bank that offers the lowest expected repayment.

Suppose that bank 1 offers a collateralized credit contract which determines a repayment, denoted by $R^{L S}$, and collateral $L=I$ that provide the same expected payoffs to a good firm as the screening contract with repayment $R^{S L}$. What would then be bank 1's profit? We have to calculate the payoffs of a good firm with different types of contracts. A good firm is indifferent between the contracts if:

$$
p\left(X-R^{L S}\right)-(1-p) I=p\left(X-R^{S L}\right)
$$

or if the collateralized contract offers $L=I$ and $R^{L S}=R^{S L}-\frac{I(1-p)}{p}$.

There is no equilibrium in pure strategies when the contract terms are determined, for the same reason as before. Each repayment has to generate a profit of $\Pi^{L S}$ for bank 1 , which is the rent a bank can demand by offering a collateralized credit contract with combination of $L$ and the highest possible repayment $R^{L S}$. Only those good firms that generated a negative signal at the competing bank will choose this contract. Therefore, this condition can be used to derive the equilibrium in mixed strategies which is shown in the next lemma.

Lemma 7. The mixed strategy equilibrium has the following features: ${ }^{5}$

(i) If $\alpha \leq \alpha_{2}=\frac{\mu s(1-s)(p X-I)+\mu s^{2} I(1-p)-I(1-\mu)(1-s)-c}{\mu s^{2} I(1-p)}$, bank 1 demands collateral $L=I$ and a repayment $R^{L S}$ from the range $\left[\underline{R}_{\alpha \leq \alpha_{2}}^{L S}, R_{M}^{L}\right]$ according to the following cumulative distribution function $F\left(R^{L S}\right)=\frac{(s-1)(p X-I)-s I(1-p)(1-\alpha)+p R^{L S}-p I}{p\left(R^{L S}-I\right)}$ and $\operatorname{prob}\left(R^{L S}=X\right)=$

\footnotetext{
${ }^{5}$ The threshold value $\alpha_{2}$ is denoted this way because it is used for comparisons in the following propositions.
} 
$\frac{(1-s)(p X-I)+s I(1-p)(1-\alpha)}{p\left(R^{L S}-I\right)}$. The expected profit of bank 1 is

$$
\Pi^{L S}=(1-s) \mu(p X-I-I(1-p)(1-\alpha)) .
$$

Bank 2 offers a screening contract and demands a repayment $R^{S L}$ from the range $\left[\underline{R}_{\alpha \leq \alpha_{2}}^{S L}, X\right]$, according to the cumulative distribution function $G\left(R^{S L}\right)=\frac{p R^{S L}-s I-(1-s)(p X)-s I(1-p)(1-\alpha)}{s\left(\left(p R^{S L}-I\right)-I(1-p)(1-\alpha)\right)}$. The expected profit of bank 2 is

$$
\Pi^{S L}=\mu s(1-s)(p X-I)-I(1-s)(1-\mu)+s^{2} \mu I(1-\alpha)(1-p)-c .
$$

(ii) If $\alpha>\alpha_{2}$, bank 1 demands collateral $L=I$ and a repayment $R^{L S}$ from the range $\left[\underline{R}_{\alpha>\alpha_{2}}^{S L}, X\right]$ and bank 2 offers a screening contract and demands a repayment $R^{S L}$ from the range $\left[\underline{R}_{\alpha>\alpha_{2}}^{S L}, X\right]$. The cumulative distribution functions are the same as in case (i). However, the expected profit of bank 2 is $\Pi^{S L}=0$.

Proof: See the Appendix.

Bank 1, which offers the collateralized credit contract, can always secure itself a positive payoff of $\Pi^{L S}$ since it has the outside option of serving all the good firms of the second group and demanding $X$ from them. As Lemma 7 shows, bank 1 will demand the repayment $\mathrm{X}$ with positive probability. The expected profit of bank 2 also depends on the liquidation value $\alpha$. For low enough liquidation values bank 2 makes positive profits as well because its screening technology involves comparatively lower costs than collateralization. Bank 2 mixes continuously over the whole range of repayments. If the liquidation value exceeds a certain threshold, collateralizing is more cost-efficient. This reduces bank 2's position in 
the competitive environment and it thus makes zero expected profits. Bank 2 demands the minimum repayment with positive probability. Moreover, the minimum repayment has to be higher than in the case of $\alpha \leq \alpha_{2}$ in order to guarantee a non-negative profit.

\subsubsection{Contract Offered}

So far, we have derived the terms of all possible combinations of contracts which can be offered. Solving the game by backward induction, we determine the type of contract which is offered in equilibrium. The banks sequentially choose the type of contract offered, with bank 1 acting first. We assume that banks offer a collateralized credit contract if both contracts generate the same return, since in case of collateralization the number of bad loans is lower. The banks compare their payoffs with the different types of contracts. Depending on the parameter values, we obtain the following equilibria:

Proposition 2. The contracts offered in equilibrium by competing banks depend on the liquidation value:

- If $\alpha<\alpha_{1}$, both banks screen.

- If $\alpha_{1} \leq \alpha<\frac{\mu s^{2} I(1-p)-\mu(p X-I)(1-s)^{2}-I(1-s)(1-2 \mu+\mu p)-c}{(1-p)\left(1-s+s^{2}\right) I \mu}$, bank 1 screens and bank 2 collateralizes.

- If $\frac{\mu s^{2} I(1-p)-\mu(p X-I)(1-s)^{2}-I(1-s)(1-2 \mu+\mu p)-c}{(1-p)\left(1-s+s^{2}\right) I \mu} \leq \alpha<\alpha_{2}$, bank 1 collateralizes and bank 2 screens.

- If $\alpha \geq \alpha_{2}$, both banks collateralize.

Proof: See the Appendix. 
Unless both banks offer a collateralized credit contract, banks are able to extract rents from their customers. This is due to the fact that for $\alpha<\alpha_{2}$, collateralization, which enables the firms to reveal their type, is relatively costly. Thus, at least one bank offers a screening contract. In this case, there is no longer perfect competition. The reason is that good firms are potentially denied credit by (at least) one bank because the signal is imperfect. If good firms receive only one credit offer, they accept the loan contract even if they have to give up the whole rent. However, the banks cannot discriminate between firms which receive an alternative offer (first group of applicants) and those who do not (second group of applicants). Therefore, they increase their repayments relative to the perfectly competitive case and make positive expected profit.

When deciding which contract to offer banks compare the profits of the different contracts. Since bank 1 moves first, it can reap a first mover advantage. Bank 2 optimizes its offer given the contract offered by bank 1 . For very low liquidation values, i.e., $\alpha<\alpha_{1}$, both banks offer a screening contract. Since screening is relatively cheaper, the profit extracted through this type of contract is high. The reason why banks can extract rents is that firms which receive an offer from one bank do not receive an offer from the other bank with certainty. Therefore, they are willing to repay as much as X. Banks exploit this situation by demanding higher repayments. If the liquidation value increases, bank 1 still offers a screening contract. But now, it is optimal for bank 2 to offer a collateralized contract since it avoids denying credit to good firms. For even higher liquidation values it is optimal for bank 1 to offer a collateralized credit contract. In order to avoid the scenario of perfect competition with zero expected profit, bank 2 offers a screening contract. Finally, if the liquidation value is above $\alpha_{2}$, both banks offer a collateralized credit contract. 


\subsection{Comparison between Monopolistic Bank and Competing Banks}

The crucial question is how the market structure in the banking sector influences the credit contract offered. To answer this question, we compare the threshold values of the liquidation values for which the contract changes under the different scenarios of competition, monopolistic bank and two banks. Thus, the threshold values for the competitive scenario are $\alpha_{1}$ and $\alpha_{2}$; for the monopolistic scenario there is only the threshold value $\alpha_{M}^{K}$.

Proposition 3. (i) Suppose that the liquidation value is very low, i.e., $\alpha<\alpha_{1}$, then the monopolistic bank offers a contract with screening and collateralization whereas the competing banks offer a screening contract.

(ii) Suppose that the liquidation value is low, i.e., $\alpha_{1} \leq \alpha<\alpha_{M}^{K}$, then the monopolistic bank offers a contract with screening and collateralization whereas in the case of competition, one bank offers a screening contract and the other bank a collateralized credit contract.

(iii) Suppose that the liquidation value is high, i.e., $\alpha_{M}^{K} \leq \alpha<\alpha_{2}$, then the monopolistic bank offers a collateralized credit contract whereas in the case of competition, again one bank offers a screening contract and the other bank a collateralized credit contract.

(iv) Suppose that the liquidation value is very high, i.e., $\alpha \geq \alpha_{2}$, then the monopolistic as well as the competing banks offer a collateralized credit contract.

Proof: See the Appendix.

The monopolistic bank is the residual claimant and therefore has to bear the costs of collateralization. Thus, it always chooses the contract with the lowest costs. As long as the liquidation value is not high, i.e., $\alpha<\alpha_{M}^{K}$, the optimal contract involves screening and offering a collateralized credit contract to all those firms that have generated a negative 


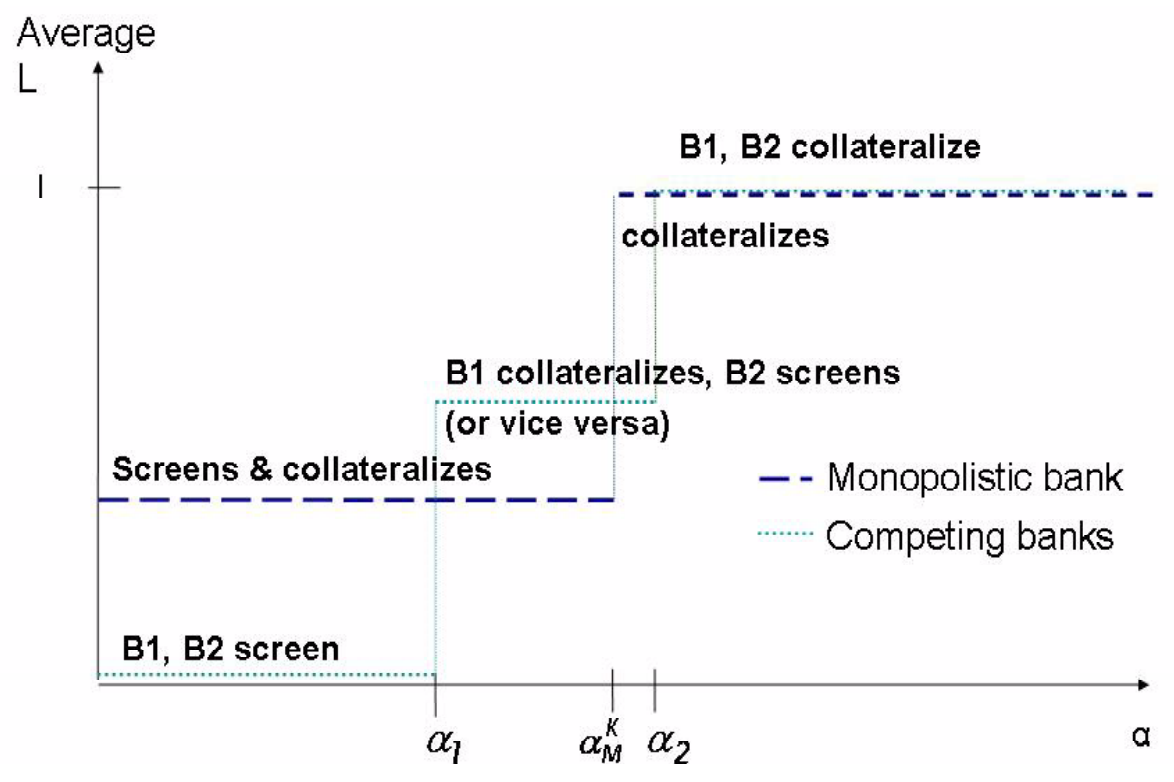

Figure 2.1: Comparison between Monopolistic Bank and Competing Banks

signal. Only if the liquidation value is high or very high does the monopolistic bank offer a collateralized credit contract, because then the expected costs of liquidating collateralized assets are lower than the costs of a screening contract (see Figure 2.1 for an illustration). The contracts offered by competing banks not only change at different threshold values than in the monopolistic case. Moreover, for very low liquidation values, both competing banks offer a screening contract. For low liquidation values, one of the banks offers a screening contract, the other one a collateralized credit contract. This asymmetry in contract offers yields positive profits to both banks. For high liquidation values, the competing banks still offer a screening and a collateralized contract whereas a monopolistic bank offers only a collateralized credit contract. The reason is that the competing banks would make zero expected profits if they both offered a collateralized contract. Therefore, they have an incentive to offer different types of contracts. Since bank 1 moves first and its offer is observable, bank 2 responds by offering a different type of contract. Thereby, each of the 
two banks makes positive expected profits. Only if the liquidation value is very high is a collateralized credit contract offered independently of the market structure.

In contrast to MPP, we find that competing banks screen less often than a monopolistic bank. The reason is that if one bank offers a screening contract and the other a collateralized contract, some degree of asymmetric information prevails as the screening signal is imperfect. Therefore, competition is less intense if both banks collateralize. Thus, the bank's incentive to soften competition drives our result whereas in MPP the inefficiency is caused by the incentive of firms to separate.

\section{Welfare Analysis}

\subsection{Optimal Contract}

We want to evaluate the contract choice in terms of efficiency. Therefore, we study a social planner that maximizes the expected payoff of investment net of any costs. In the context of our model, the costs of financing depend on the degree of competition and the type of contract offered (which is denoted by $V$ ). Both determinants are influenced by the size of the costs of collateralization relative to the screening costs. ${ }^{6}$ In the case of a monopolistic bank social welfare is given by:

$$
S W \begin{cases}=\Pi_{M}^{S L}=\mu(p X-I)-(1-s) I((1-\mu)-\mu(1-p)(1-\alpha))-c & \text { if } V=S, L \\ =\Pi_{M}^{L}=\mu(p X-I-I(1-p)(1-\alpha)) & \text { if } V=L\end{cases}
$$

\footnotetext{
${ }^{6}$ Note that in this model the liquidation value represents the proceeds the bank receives as creditor. The social costs from liquidation might well be lower than the deadweight loss from liquidation. The reason is that the buyer of the asset may have a higher willingness to pay than is reflected by the liquidation value.
} 
In the case of bank competition social welfare is given by:

$$
S W \begin{cases}=s(2-s) \mu(p X-I)-\left(1-s^{2}\right)(1-\mu) I-2 c & \text { if } V=S \\ <\Pi_{M}^{S L}=\mu(p X-I)-(1-s) I((1-\mu)-\mu(1-p)(1-\alpha))-c & \text { if } V=S, L \\ =\mu(p X-I-I(1-p)(1-\alpha)) & \text { if } V=L\end{cases}
$$

If both banks screen, $s(2-s)$ good firms that contribute to social welfare, and $\left(1-s^{2}\right)$ bad firms that reduce social welfare, receive loans. If one bank collateralizes and the other bank screens, we only state the upper bound of social welfare. This upper bound is identical to the social welfare in the case of a monopolistic bank. The monopolistic bank offers collateralization to those firms which generate a negative signal. Only the good firms among them are willing to offer collateral. In the case of bank competition, the firms demand credit from the bank with the lowest offer. Since banks mix over repayments, it is not clear which bank wins a customer, i.e., whether a customer that gets two offers is served by the bank with the lowest cost contract. Therefore, the actual social welfare depends on which bank wins the competition and, thus, on the cumulative density functions of both banks. In order to facilitate the exposition of the social welfare function, we only show the upper bound. If both banks collateralize, all good firms contribute to social welfare, which is reduced by the costs of collateralization.

What is the socially optimal structure of the banking sector and which contracts are offered? The answer is provided in the following proposition:

Proposition 4. (i) If the liquidation value is below the lower threshold value, i.e., $\alpha \leq$ $\frac{(1-s)(-(1-s) \mu(p X-I)+I((\mu(1-p)-(1-\mu) s)))-c}{\mu(1-p)(1-s) I}$, the social planner allows two banks to enter the market which offer a screening contract and produce two independent signals.

(ii) If the liquidation value is intermediate, i.e., $\frac{(1-s)(-(1-s) \mu(p X-I)+I((\mu(1-p)-(1-\mu) s)))-c}{\mu(1-p)(1-s) I}<\alpha \leq$ 
$\alpha_{2}$, the social planner allows market entry of only one bank. The monopolistic bank offers a screening contract with collateralization for $\alpha \leq \alpha_{M}^{K}$ and a collateralized credit contract for $\alpha_{M}^{K}<\alpha \leq \alpha_{2}$

(iii) If the liquidation value is above the higher threshold, i.e., $\alpha>\alpha_{2}$, then the social planner is indifferent between a banking market with one or two banks since both offer a collateralized credit contract and produce the same social welfare.

Proof: See the Appendix.

As part (i) of the proposition states, below a certain threshold value collateralization is very expensive. The monopolistic bank offers a screening contract with the option to collateralize whereas competing banks offer only screening contracts. Note that both banks generate signals on the creditworthiness of a borrower independently of each other and that the second signal is such that financing firms according to this signal increases welfare. Consequently, the behavior of a monopolistic bank is less efficient than the behavior of competing banks.

For intermediate liquidation values (part (ii)), a monopolistic bank generates higher social welfare. Since the competing banks randomize on their repayments, it is not possible to assure that the screening contract, which is the type of contract causing the lower costs, is preferred by the firms. Due to competition, the firms demand credit from the bank with the lowest offer, which is not necessarily made by the bank with the lowest cost of generating information. However, a monopolistic bank minimizes this cost and is therefore preferred by the social planner. Finally, if the liquidation value exceeds the threshold value of $\alpha_{2}$ (part (iii)), the terms of a credit contract are independent of the degree of competition. Therefore, a social planner is indifferent between market structures. 


\subsection{Discussion of Results}

In our analysis we assumed that financing the applicants from the second group which generate a positive signal yields a non-negative profit for the bank, or $\bar{\Pi}^{S}=(1-s) s(\mu(p X-I)-(1-\mu) I)-c \geq 0$. How would the results change if we abandon this assumption? Then, generating a second signal is inefficient and social welfare is maximized if there is only one bank. The simulation for the Belgian banking sector offers some indication on the quality of the screening signal. According to Mitchell and van Roy (2007), $(1-s) s \approx 0.2$ implying that $s \approx 0.7$. However, in many countries, in particular in emerging markets, the screening technology of banks is often not very sophisticated yet (or

$s$ is lower). Since $\frac{\partial \bar{\Pi}^{S}}{\partial s}<0$, it should be efficient from a social welfare perspective to have more than one signal on the firm's creditworthiness.

In order to make our results as clear as possible, we restrict our analysis to only two banks. The same intuition would apply to a banking sector with more banks. The condition on the number $n$ of banks active in the market is that the $n t h$ signal generated yields a non-negative payoff for the bank which bases its lending decision on this signal.

Moreover, we set up a model in which the decisions about the type of the credit contract offered are made sequentially. In a game with simultaneous offers, both banks would offer screening and collateralized contracts with positive probability. We would obtain an equilibrium in mixed strategies for the type of contract offered. Thus, the qualitative features of our model remain the same. Also, the threshold values where the banks' choice switches from offering a screening contract only to offering different contracts $\left(\alpha_{1}\right)$, and from offering different contracts to collateralized contracts only $\left(\alpha_{2}\right)$ do not change. However, the amount of social welfare changes if bank 1 and bank 2 randomize over the choice of contracts. But 
in this parameter range, the monopolistic bank still remains optimal from a social welfare perspective and thus our welfare results are robust to changes in the timing of the choice of contracts.

We made two assumptions that are in favor of a monopolistic bank. First, we assumed that the monopolistic bank can offer a collateralized contract to those firms that generated a bad signal. This assumption increases the welfare in the case of a monopolistic bank as the liquidation value is rather low. Despite this assumption which is in favor of the monopolistic bank, we find a parameter range (see Proposition 4, condition (i)) where competing banks generate a higher social welfare. Without this assumption, this parameter range would be even larger. Second, we assumed that a monopolistic bank has an incentive to offer a screening contract with the additional possibility to collateralize even if the liquidation value is very low. Suppose that this assumption does not hold. Then, for very low liquidation values it would be optimal for the monopolistic bank to offer a screening contract. In this case, social welfare would definitely be lower in the case of the monopolistic bank as producing a second screening signal increases welfare.

\section{Conclusion}

We started out with the question of how desirable collateralization is and how bank competition influences a bank's choice between a screening and a collateralized contract. We find that the monopolistic offers a collateralized contract if it is efficient. However, competing bank offer collateralized contracts less often than a monopolistic bank. Our analysis has important implications for the desirability of bank competition. Most other papers, including MPP, show that only a monopolistic bank offers the first best contract for the whole parame- 
ter range. Our analysis goes one step further and compares the effects of bank competition for different liquidation values (relative to the bank's screening skills). For high liquidations values the degree of bank competition does not play a role for the efficiency of the provision of loans. This is the case for industries in developed economies where highly liquid assets are used as collateral. For intermediate liquidation values, we indeed find that a monopolistic bank is superior as it offers the first best contract. For very low liquidation values, however, bank competition generates higher levels of social welfare. Competition allows generation of more than one signal on the profitability of a project. If the quality of the signal is rather low, it is desirable for a firm and, even more importantly, for the social planner to have more than one bank that screens. Suppose there is only a monopolistic bank with a mediocre screening technology. Then, this single screening result alone would determine whether a firm gets a loan or not.

In emerging markets, in particular, we expect to find situations where the liquidation value is low in absolute and in relative terms and the screening technique is mediocre. With competition and the same mediocre screening technology, a creditworthy firm has a second chance if the test provides an incorrect signal. Thus, by explicitly taking into account the difference in liquidation values, we demonstrate that the results crucially depend on the parameter range. This implies that policy recommendations will differ significantly across economies. Moreover, as banks, in particular in developed economies, take many different types of assets as collateral and thus the liquidation values differ substantially, there is no clear-cut policy recommendation on the desired level of bank competition. However, policy makers could improve the situation by increasing the assets' liquidation values, for instance, by increasing the liquidity of secondary markets. 
The welfare analysis clearly shows that social welfare increases in the liquidation values. One obvious reason is that the losses through liquidation decrease. But higher liquidation values have the additional advantage that independent of the degree of bank competition the efficient contract is offered. The policy recommendations depend on the source for costs of liquidation. In developed economies, liquidation values of assets are low if assets are traded on illiquid secondary markets. In particular, in times of financial crises secondary markets can be illiquid. Banks will take into account such a situation when evaluating the expected liquidation value of collateral. Governments should take actions that help to increase the liquidity of secondary markets. In emerging markets, low liquidation values are in addition caused by the poor legal and institutional environment. The most fundamental measure is thus to establish secure property rights as a prerequisite for collateralization, for instance, by making cadastre work. In addition, measures should be taken that reduce the costs of collateralization, for example, by speeding up the decision of courts. 


\section{Appendix}

\subsection{Proof of Proposition 1}

We want to show that $\Pi_{M}^{S}<\Pi_{M}^{S L}$. Therefore we compare

$$
\begin{aligned}
\Pi_{M}^{L} & =\mu(p X-(1-p)(1-\alpha) I-I) \\
& \geq \mu(p X-I)-(1-\mu) I(1-s)-c-(1-s) \mu I(1-p)(1-\alpha)=\Pi_{M}^{S L}
\end{aligned}
$$

for $\alpha_{M}^{K}$ described in the proposition.

Q.E.D.

\subsection{Proof of Lemma 5}

We determine the equilibrium in mixed strategies as described in the lemma.

- If the bank offers the lowest repayment $\underline{R}^{S}$, it will attract all firms that are offered credit by the competitor and, of course, the firms that do not have an alternative offer. The bank's expected payoff is:

$$
\begin{aligned}
& \left\{\mu\left(s^{2}\left(p \underline{R}^{S}-I\right)\right)-(1-\mu)(1-s)^{2} I\right\} \\
+ & \left\{\mu(1-s) s\left(p \underline{R}^{S}-I\right)-(1-\mu) s(1-s) I\right\}-c \\
= & \bar{\Pi}^{S}
\end{aligned}
$$

The first brace captures the expected payoff from the first group of applicants, the second those of the second group. All firms from the first group demand credit from this bank because it demands the lowest repayment. Good firms among the applicants from the first group will receive credit with probability $s^{2}$. Bad firms are financed with probability $(1-s)^{2}$. The probabilities $s^{2}$ and $(1-s)^{2}$ are the probabilities with which 
good and bad firms, respectively, receive offers from both banks. The second group consists of all firms that are denied credit by the competing bank. Thus, it consists of a share of $\mu(1-s)$ good firms and $(1-\mu) s$ bad firms. Only those of the second group that were already rejected by the competitor and now generate a positive signal receive a loan. The minimum repayment is given by $\underline{R}^{S}=\frac{s(\mu p X-I)(1-s)+I(1-s(1-\mu)-\mu(1-s))}{\mu s p}$.

- Consider the profit function of bank $i(i \neq j)$ conditional on bank $j$ 's offer.

$$
\begin{aligned}
\Pi_{i}\left(R_{i}\right)= & \left(1-F_{j}\left(R_{i}\right)\right)\left(\mu s^{2}\left(p R_{C}^{S}-I\right)-(1-\mu)(1-s)^{2} I\right)+ \\
& \left(\mu(1-s) s\left(p R_{C}^{S}-I\right)-(1-\mu) s((1-s) I)\right)-c \forall R_{i} \epsilon\left[\underline{R}_{C}^{S}, X\right) .
\end{aligned}
$$

Let us use the fact that $\Pi_{i}\left(R_{j}\right)=\bar{\Pi}_{C}^{S}$ for each repayment.

- For bank $j$ we determine $F_{j}\left(R_{i}\right)$ by setting

$$
\begin{aligned}
\Pi_{i}\left(R_{i}\right)= & \left(1-F_{j}\left(R_{i}\right)\right)\left(\mu s^{2}\left(p R_{C}^{S}-I\right)-(1-\mu)(1-s)^{2} I\right) \\
& +\left(\mu(1-s) s\left(p R_{C}^{S}-I\right)-(1-\mu) s(1-s) I\right)-c=\bar{\Pi}_{C}^{S}
\end{aligned}
$$

Since both banks are identical $F_{j}\left(R_{i}\right)=F_{i}\left(R_{j}\right) \equiv F(R)$ with $F(R)=\frac{\mu s^{2}(p R-I)-I(1-\mu)(1-s)^{2}-\mu s(1-s) p(X-R)}{\mu s^{2}(p R-I)-I(1-\mu)(1-s)^{2}}$. Thus, both banks demand a repayment from the range $\left[\frac{s(\mu p X-I)(1-s)+I(1-s(1-\mu)-\mu(1-s))}{\mu s p}, X\right]$ according to $F(R)$. Note that $F(X)=1$. Q.E.D.

\subsection{Proof of Lemma 6}

Good firms receive the expected payoff of $p\left(X-E\left(R^{S}\right)\right)$ with probability $s(2-s)$. The profit of the bank is the expected interest rate revenue net of the losses from financing bad borrowers and the screening costs.

Q.E.D. 


\subsection{Proof of Lemma 7}

Step 0: We argue that there is no equilibrium in pure strategies. Suppose bank 1 offers a collateralized contract and bank 2 a screening contract. Assume that both banks demand the same expected repayment. The first group of applicants would go to each bank with equal probability. Suppose that this repayment yields zero expected profit for bank 1. Bank 2 could marginally undercut this price and would make a positive profit because all applicants from the first group would apply for credit at this bank. However, for bank 1 it would be optimal to serve all those good firms that were denied credit by bank 2. From these firms bank 1 could extract all rents by demanding repayment $R^{L S}=R_{M}^{L}=\frac{p X-(1-p) I}{p}$ and $L=I$. Then, the profit of bank 1 is $\Pi^{L S}=\mu(1-s)(p X-I-I(1-p)(1-\alpha))$. The best response of bank 2 to $\left\{R^{L S}=R_{M}^{L} ; L=I\right\}$ would be to demand repayment $R^{S L}=X-\varepsilon$. Thus, no equilibrium in pure strategies exists.

Step 1: Determine the expected for bank 1 if it demands the highest repayment $R^{L S}=$ $\frac{p X-(1-p) I}{p}$ and collateral $L=I$ and serves only second round applicants because it is undercut by bank 2 .

Then, the payoff of bank 1 which offers a collateralized contract provided that bank 2 offers a screening contract is given by:

$$
\begin{aligned}
\bar{\Pi}^{L S} & =\mu(1-s)\left(p\left(\frac{p X-(1-p) I}{p}\right)+(1-p) \alpha I-I\right) \\
& =\mu(1-s)(p X-I-I(1-p)(1-\alpha))
\end{aligned}
$$

We assume that $\bar{\Pi}^{L S}>0$. Suppose that bank 1 serves the whole market. The lowest repayment bank 1 demands is determined by the expected profit $\bar{\Pi}^{L S}$. Thus, $\underline{R}^{L S}$ is given 
by

$$
\Pi^{L S}=\mu\left(p \underline{R}^{L S}+(1-p) \alpha I-I\right)=\mu(1-s)(p X-I-I(1-p)(1-\alpha))
$$

Therefore, the contract with the lowest repayment specifies $\left\{\underline{R}^{L S}=\frac{(1-s) \mu(p X-I)+\mu s I(1-p)(1-\alpha)+\mu p I}{p \mu}, I\right\}$. The debtor is indifferent between this collateralized credit contract and a screening contract if the repayment with a screening contract is $\underline{R}^{S L}=\frac{p X(1-s)+s I(1-p)(1-\alpha)+s I}{p}$.

Step 2: We assume that for bank $1, \Pi^{L S}\left(\underline{R}^{L S}\right)>0$, and determine the mixed strategies for bank 2 as described in Lemma 7.

The cumulative distribution function for bank 2, denoted by $G(R)$, is given by the following condition:

$$
\begin{aligned}
\bar{\Pi}^{L S}= & (1-G)\left(\mu\left(p R^{S L}+(1-p) \alpha I-I\right)\right)+G(1-s)\left(\mu\left(p R^{S L}+(1-p) \alpha I-I\right)\right) \text { or } \\
& (1-G)\left(\mu\left(p R^{S L}+(1-p) \alpha I-I\right)\right)+G(1-s)\left(\mu\left(p R^{S L}+(1-p) \alpha I-I\right)\right) \\
= & \mu(1-s)(p X-I-I(1-p)(1-\alpha))
\end{aligned}
$$

As a result, $G\left(R^{S L}\right)=\frac{p R^{S L}-s I-(1-s)(p X)-s I(1-p)(1-\alpha)}{s\left(\left(p R^{S L}-I\right)-I(1-p)(1-\alpha)\right)}$.

Step 3: Suppose $\alpha \leq \alpha_{2}=\frac{\mu s(1-s)(p X-I)+\mu s^{2} I(1-p)-I(1-\mu)(1-s)-c}{\mu s^{2} I(1-p)}$ implying that $\Pi^{S L}\left(\underline{R}^{S L}=\frac{p X(1-s)+s I(1-p)(1-\alpha)+s I}{p}\right)>0$. We determine the equilibrium in mixed strategies as described in the Lemma 7 (i).

The expected profit of bank 2 demanding $\underline{R}^{S L}=\frac{p X(1-s)+s I(1-p)(1-\alpha)+s I}{p}$ is given by

$$
\begin{aligned}
\bar{\Pi}^{S L} & =\mu s(1-s)\left(p\left(\frac{p X(1-s)+s I(1-p)(1-\alpha)+s I}{p}\right)-I\right)-I(1-s)(1-\mu)-c \\
& =\mu s(1-s)(p X-I)-I(1-s)(1-\mu)+s^{2} \mu I(1-\alpha)(1-p)-c
\end{aligned}
$$


Note that $\Pi^{S L}>0$ if $\alpha \leq \alpha_{2}=\frac{\mu s(1-s)(p X-I)+\mu s^{2} I(1-p)-I(1-\mu)(1-s)-c}{\mu s^{2} I(1-p)}$.

The cumulative distribution function for bank 1, denoted by $F(R)$, is determined by:

$$
\begin{aligned}
\Pi^{S L} & =(1-F)\left(\mu\left(s\left(p R^{L S}-I\right)\right)-(1-\mu)((1-s) I)\right)+F(-(1-\mu)((1-s) I))-c \\
& =\mu s(1-s)(p X-I)-I(1-s)(1-\mu)+s^{2} \mu I(1-\alpha)(1-p)-c
\end{aligned}
$$

As as result, $F\left(R^{L S}\right)=\frac{(s-1)(p X-I)-s I(1-p)(1-\alpha)+p R^{L S}-p I}{p\left(R^{L S}-I\right)}$. Bank 1 demands collateral $L=$ $I$ and repayments from the range $\left[\underline{R}^{L S}, \frac{p X-(1-p) I}{p}\right]$. Note that $F\left(\frac{(1-s) \mu(p X-I)+\mu s I(1-p)(1-\alpha)+\mu p I}{p \mu}\right)=$ 0 and $F\left(\frac{p X-(1-p) I}{p}\right)<1$. Thus, with probability $1-F\left(\frac{p X-(1-p) I}{p}\right)$ bank 1 demands $\frac{p X-(1-p) I}{p}$ as a repayment.

Bank 2 demands a repayment $R^{S L}$ from the range $\left[\underline{R}^{S L}, X\right]$, according to the cumulative distribution function $G\left(R^{S L}\right)=\frac{p R^{S L}-s I-(1-s)(p X)-s I(1-p)(1-\alpha)}{s\left(\left(p R^{S L}-I\right)-I(1-p)(1-\alpha)\right)}$. Note that $G\left(\underline{R}^{S L}\right)=0$ and $G(X)=1$

Step 4: Suppose $\alpha>\alpha_{2}$ implying that $\Pi^{L S}\left(\underline{R}^{S L}=\frac{p X(1-s)+s I(1-p)(1-\alpha)+s I}{p}\right) \leq 0$. We determine the equilibrium in mixed strategies as described in Lemma 7 (ii).

Thus, bank 2 needs at least a repayment of $\underline{R}^{S L}=\frac{I(1-\mu)(1-s)+\mu s I+c}{\mu s p}$ in order to breakeven. Thus, its expected profit is $\Pi^{L S}=0$. A debtor is indifferent between a screening contract determining $R^{S L}=\frac{I(1-\mu)(1-s)+\mu s I+c}{\mu s p}$ and a collateralized credit contract with $\left\{L=I, R^{L S}=\frac{I(1-\mu)(1-s)+\mu s p I+c}{\mu p s}\right\}$. The latter condition therefore determines the lower bound of the range from which bank 1 demands its repayment.

The cumulative distribution function for bank 1, denoted by $F(R)$, is determined by:

$$
(1-F)\left(\mu\left(s\left(p R^{L S}-I\right)\right)-(1-\mu)((1-s) I)\right)+F(-(1-\mu)((1-s) I))-c=0
$$


As a result, $F\left(R^{L S}\right)=\frac{\mu s p R^{L S}-\mu s I-\mu s I p-I+I s+I \mu-c}{\mu s p\left(R^{L S}-I\right)}$. Bank 1 demands collateral $L=I$ and repayments from the range $\left[\underline{R}^{L S}, \frac{p X-(1-p) I}{p}\right]$. Note that $F\left(\underline{R}^{L S}\right)=0$ and $F\left(\frac{p X-(1-p) I}{p}\right)<1$. Thus, with probability $1-F(X)$ bank 1 demands $\frac{p X-(1-p) I}{p}$ as a repayment.

Bank 2 demands a repayment $R^{S L}$ from the range $\left[\underline{R}^{S L}, X\right]$, according to the following cumulative distribution function

$G\left(R^{S L}\right)=\frac{p R^{S L}-s I-(1-s)(p X)-s I(1-p)(1-\alpha)}{s\left(\left(p R^{S L}-I\right)-I(1-p)(1-\alpha)\right)}$. Note that $G\left(\underline{R}^{S L}\right)>0$ and $G(X)=1$. Q.E.D.

\subsection{Proof of Proposition 2}

The profit when a screening contract is offered is $\Pi^{S}$. The profit with a collateralized contract is $\Pi^{L}$. The bank obtains a profit of $\Pi^{S L}$ if it screens and the competitor collateralizes and a profit of $\Pi^{L S}$ if it collateralizes when the competitor screens. We first investigate when it is optimal for bank 1 to offer a screening contract and state the result in the following lemma.

Lemma 8. Suppose bank 2 offers a screening contract. It is optimal for bank 1 to offer a screening contract if $\alpha<\alpha_{1}=\frac{\mu(2 s-1)(p X-I)+I \mu(1-p)(1-s)-s^{2}(\mu p X-I)-s I(1-\mu)-c}{I \mu(1-p)(1-s)}$ and to offer a collateralized contract if $\alpha \geq \alpha_{1}$.

Proof: Suppose bank 1 intends to screen. We compare bank 1's profit if bank 2 collateralizes $\left(\Pi^{L S}\right)$ and if bank 2 screens as well $\left(\Pi^{S}\right)$. We can show that

$$
\begin{aligned}
& \Pi^{L S}-\Pi^{S} \\
= & (1-s) \mu(p X-I-I(1-p)(1-\alpha)) \\
& -(\mu(1-s)(s(p X-I))-(1-\mu) s((1-s) I)-c)
\end{aligned}
$$

which is positive if $\alpha \geq \alpha_{1}=\frac{\mu(2 s-1)(p X-I)+I \mu(1-p)(1-s)-s^{2}(\mu p X-I)-s I(1-\mu)-c}{I \mu(1-p)(1-s)}$. 
Q.E.D.

Bank 1 takes the reaction of bank 2 into consideration if it decides on the type of contract it offers. Provided that bank 2 offers a screening contract, bank 1 offers a screening contract as well as long as the screening costs are relatively low. Bank 1 chooses to offer a collateralized contract, if screening becomes relatively more costly as the liquidation value increases.

Bank 1 first determines the type of contract it offers. Then bank 2 decides. Thus, bank 1 takes into account the decision of bank 2. Therefore, we solve the problem by backward induction.

(1) Suppose $\alpha<\alpha_{1}$ :

The payoffs for bank 2 are

- if both banks offer a screening contract:

$$
\Pi^{S}=\mu(1-s)(s(p X-I))-(1-\mu) s((1-s) I)-c
$$

- if bank 1 offers a screening contract and bank 2 a collateralized contract:

$$
\Pi^{L S}=\mu(1-s)(p X-I-I(1-p)(1-\alpha))
$$

- if bank 1 offers a collateralized contract and bank 2 a screening contract:

$$
\Pi^{S L}=\mu s(1-s)(p X-I)-I(1-s)(1-\mu)+s^{2} \mu I(1-\alpha)(1-p)-c
$$

- if both banks offer a collateralized contract: $\Pi^{L}=0$

Thus, the best response of bank 2 is

- to offer a screening contract if bank 1 offers a collateralized contract as $\Pi^{S L}>\Pi^{L}$.

- to offer a screening contract if bank 1 offers a screening contract as $\Pi^{S}>\Pi^{L S}$. 
For bank 1 it is optimal to offer a screening contract as $\Pi^{S}>\Pi^{L}=0$. In equilibrium, both banks offer a screening contract.

(2) Suppose $\alpha_{1} \leq \alpha<\frac{\mu s^{2} I(1-p)-\mu(p X-I)(1-s)^{2}-I(1-s)(1-2 \mu+\mu p)-c}{(1-p)\left(1-s+s^{2}\right) I \mu}$ :

The payoffs for bank 2 are the same as in case (1).

Thus, the best response of bank 2 is

- to offer a collateralized contract if bank 1 offers a screening contract as $\Pi^{L S}>\Pi^{S}$.

- to offer a screening contract if bank 1 offers a collateralized contract as $\Pi^{S L}>\Pi^{L}=0$.

Bank 1 prefers offering a screening contract provided that $\Pi^{S L}-\Pi^{L S}>0$.

This is the case if $\alpha<\frac{\mu s^{2} I(1-p)-\mu(p X-I)(1-s)^{2}-I(1-s)(1-2 \mu+\mu p)-c}{(1-p)\left(1-s+s^{2}\right) I \mu}$.

For bank 1 it is optimal to offer a screening contract as $\Pi^{S L}>\Pi^{L S}$. In equilibrium, bank 1 screens and bank 2 collateralizes.

(3) Suppose $\frac{\mu s^{2} I(1-p)-\mu(p X-I)(1-s)^{2}-I(1-s)(1-2 \mu+\mu p)-c}{(1-p)\left(1-s+s^{2}\right) I \mu} \leq \alpha<\alpha_{2}$ :

The payoffs for bank 2 and its best response are the same as in case (2).

For bank 1 it is optimal to offer a collateralized contract as $\Pi^{L S}>\Pi^{S L}$. In equilibrium, bank 1 collateralizes and bank 2 screens.

(4) Suppose $\alpha \geq \alpha_{2}$ :

The payoffs for bank 2 are

- if both banks offer a screening contract:

$$
\Pi^{S}=\mu(1-s)(s(p X-I))-(1-\mu) s((1-s) I)-c
$$


- if bank 1 offers a screening contract and bank 2 a collateralized contract:

$\Pi^{L S}=\mu(1-s) \mu(p X-I-I(1-p)(1-\alpha))$

- if bank 1 offers a collateralized contract and bank 2 a screening contract: $\Pi^{S L}=0$

- if both banks offer a collateralized contract: $\Pi^{L}=0$

Thus, the best response of bank 2 is

- to either offer a screening contract or a collateralized contract if bank 1 offers a collateralized contract as $\Pi^{S L}=\Pi^{L}=0$. We assumed that a bank offers a collateralized contract if it is indifferent between the contracts because with collateralization the number of bad loans is minimized.

- to offer a collateralized contract if bank 1 offers a screening contract as $\Pi^{L S}>\Pi^{S}$.

Thus, offering a collateralized contract is the dominant strategy for bank 2 .

Bank 1 is indifferent between screening and collateralizing as $\Pi^{S L}=\Pi^{L}=0$ and, due to our assumption, offers a collateralized credit contract. In equilibrium, both banks collateralize.

Q.E.D.

\subsection{Proof of Proposition 3}

(1) We show that $\alpha_{1}<\alpha_{M}^{K}$ :

$$
\begin{aligned}
& \alpha_{M}^{K}-\alpha_{1}=\frac{\mu I(1-s p)-(1-s) I-c}{\mu s I(1-p)}-\frac{\mu(2 s-1)(p X-I)+I \mu(1-p)(1-s)-s^{2}(\mu p X-I)-s I(1-\mu)-c}{I \mu(1-p)(1-s)}= \\
& \frac{\mu I-3 \mu I s-I+2 I s-c+2 c s-2 s^{2} \mu p X+2 \mu I s^{2}+\mu s p X+s^{3} \mu p X-s^{3} I}{\mu s I(1-p)(1-s)} \\
& \text { as } \mu I-2 \mu I s-I+2 I s-c+2 c s-2 s^{2} \mu p X+2 \mu I s^{2}+\mu s p X-\mu I s+s^{3} \mu p X-s^{3} I=
\end{aligned}
$$




$$
(1-s)\left(\mu s(1-s)(p X-I)+I(1-\mu)\left(s+s^{2}-1\right)\right)+c(2 s-1)>0
$$

We know that $\left(s+s^{2}-1\right)>0$ if $s>0.61803$ and the difference must be positive as all terms are positive. By inserting the lowest value of the screening quality, $s=0.5$, which yields a difference of $0.125(\mu p X-I)>0$, we show that the difference will always be positive.

(2) We show that $\alpha_{M}^{K}<\alpha_{2}$ :

$$
\begin{aligned}
& \alpha_{2}-\alpha_{M}^{K}=\frac{\mu s(1-s)(p X-I)+\mu s^{2} I(1-p)-I(1-\mu)(1-s)-c}{\mu s^{2} I(1-p)}-\frac{\mu I(1-s p)-(1-s) I-c}{\mu s I(1-p)}= \\
& (1-s) \frac{\mu s p X-2 \mu I s+I s+\mu I-I-c}{\mu s^{2} I(1-p)} \\
& \text { as } \mu s p X-\mu I s-\mu I s+I s+\mu I-I-c=s \mu(p X-I)-(1-\mu)(1-s) I-c=\Pi_{M}^{S}>0
\end{aligned}
$$

By comparing the threshold values derived in the previous propositions cases (i) to (iv) can be discriminated.

Q.E.D.

\subsection{Proof of Proposition 4}

The social planner compares social welfare for the different values of $\alpha$.

For low values of $\alpha$, the monopolistic bank offers a screening contract with the option to collateralize. The competing banks both offer a screening contract. Comparing resulting social welfare functions yields:

$$
\begin{aligned}
& S W_{M}-S W \\
= & (\mu(p X-I)-(1-\mu)(1-s) I-(1-s) \mu(1-p)(1-\alpha) I-c) \\
& -\left(s(2-s) \mu(p X-I)-\left(1-s^{2}\right)(1-\mu) I-2 c\right)
\end{aligned}
$$

which is negative if $\alpha \leq \frac{(1-s)(-(1-s) \mu(p X-I)+I((\mu(1-p)-(1-\mu) s)))-c}{\mu(1-p)(1-s) I}$. For liquidation values below this threshold, the social planner prefers competing banks that both offer screening contracts. Above this threshold value, the social planner prefers a monopolistic bank. 
Next, the social planner compares social welfare generated by a monopolistic bank, offering a screening contract with the option to collateralize, and competing banks when one of them offers a screening contract and the other one a collateralized contract. This comparison is valid for the parameter range $\frac{(1-s)(-(1-s) \mu(p X-I)+I((\mu(1-p)-(1-\mu) s)))-c}{\mu(1-p)(1-s) I}<\alpha \leq \alpha_{M}^{K}$. Since $S W<S W_{M}=(\mu(p X-I)-(1-\mu)(1-s) I-(1-s) \mu(1-p)(1-\alpha) I-c)$, it is obvious that the social planner prefers a monopolistic bank. For liquidation values $\alpha_{M}^{K}<\alpha \leq \alpha_{2}$, the monopolistic bank offers a screening contract with the option to collateralize, the competing banks offer a screening and a collateralized contract. Since a monopolistic bank decides to switch from a collateralized contract with the option to screen to a collateralized contract, the latter contract yields the highest social welfare. Therefore, social welfare is maximized by a monopolistic bank.

Finally, the social planner compares social welfare if a collateralized contract is offered. In this case $S W=\mu(p X-I-I(1-p)(1-\alpha))$, independently of the number of banks. Therefore, the social planner is indifferent between a monopolistic bank and competing banks. A collateralized contract is offered independently of the number of banks if $\alpha>\alpha_{2}$.

Q.E.D. 


\section{References}

Berlin, Mitchell and Butler, Alexander W. (2002): Collateral and Competition, Federal Reserve Bank of Philadelphia Working Paper No. 02-22, Philadelphia.

Besanko, David, and Thakor, Anjan V. (1987): Collateral and Rationing: Sorting Equilibria in Monopolistic and Competitive Credit Markets, International Economic Review 28, 3:671-689.

Bester, Helmut (1985): Screening and Rationing in Credit Markets with Imperfect Information, American Economic Review 75, 4:850-855.

Bester, Helmut (1987): The Role of Collateral in Credit Markets with Imperfect Information, European Economic Review 31, 4:887-899.

Bester, Helmut (1994): The Role of Collateral in a Moral Hazard Model of Debt Renegotiation, Journal of Money, Credit, and Banking 26, 1:72-86.

Boyd, John and De Nicolò, Gianni (2005): The Theory of Bank Risk-Taking and Competition Revisited, Journal of Finance 60, 3:1329-1343.

Broecker, Thorsten (1990): Credit-Worthiness Tests and Interbank Competition, Econometrica 58, 2:429-452.

Cetorelli, Nicola (2001): Competition Among Banks: Good or Bad?, Economic Perspectives, Federal Reserve Bank of Chicago, Q2/2001, 38-48.

Dell'Ariccia, Giovanni, and Marquez, Robert (2006): Lending Booms and Lending Standards, Journal of Finance 61, 5:2511-2546.

Dell'Ariccia, Giovanni, Friedman, Ezra und Marquez, Robert (1999), Adverse selection as a Barrier to Entry in the Banking Industry, RAND Journal of Economics 30, 3:515-534. 
Hainz, Christa (2003): Bank Competition and Credit Markets in Transition Economies, Journal of Comparative Economics 31, 223-45.

Inderst, Roman and Müller, Holger M. (2006): A Lender-Based Theory of Collateral, Journal of Financial Economics 84, 826-859.

Jackson, Thomas H. (1986): The Logic and Limits of Bankruptcy Law, Cambridge, Mass.: Harvard University Press, 1986.

Jacobson, Tor, Lindé, Jesper, and Roszbach, Kaspar (2006): Internal Rating Systems, Implied Credit Risk and the Consistency of Banks' Risk Classification Policies, Journal of Banking and Finance 30, 1899-1926.

Manove, Michael, Padilla, A. Jorge, and Pagano, Marco (2001): Collateral versus Project Screening: A Model of Lazy Banks, RAND Journal of Economics 32, 4:726-44.

Manove, Michael and Padilla, A. Jorge (1999): Banking (Conservatively) with Optimists, RAND Journal of Economics 30, 2:324-50.

Mitchell, Janet and van Roy, Patrick (2007): Failure Prediction Models: Performance, Disagreement, and Credit Quality, unpublished manuscript, National Bank of Belgium.

Saunders, Anthony and Thomas, Hugh (2001): Financial Institutions Management, Second Canadian Edition, Mc Graw Hill Ryerson: Toronto.

Schnitzer, Monika (1999a): On the Role of Bank Competition for Corporate Finance and Corporate Control in Transition Economies, Journal of Institutional and Theoretical Economics 155, 1:23-50.

Schnitzer, Monika (1999b): Bank Competition and Enterprise Restructuring in Transition Economies, Economics of Transition 7, 133-55. 
Sengupta, Rajdeep (2007): Foreign Entry and Bank Competition, Journal of Financial Economics 84, 2:502-528.

Sharpe, Steven A. (1990): Asymmetric Information, Bank Lending, and Implicit Contracts: A Stylized Model of Customer Relationships, Journal of Finance 45, 1069-87.

World Bank (2001): World Development Report 2002: Building Institutions for Markets, Oxford University Press, Worldbank: Washington D.C., September 2001.

World Bank (2006): Doing Business Report, http://www.doingbusiness.org/.

Wu, Brian and Knott, Anne Marie (2006): Entrepreneurial Risk and Market Entry, Management Science 52, 9:1315-30.

Zazzaro, Alberto (2005): Should Courts Enforce Credit Contracts Strictly?, Economic Journal 115, 166-184. 